\title{
LEXICAL RETRIEVAL STAGES OF MOMENTARILY INACCESSIBLE FOREIGN LANGUAGE WORDS ${ }^{1}$
}

Peter Ecke

Universidad de las Américas

Merrill F. Garrett

University of Arizona

\section{Introduction}

The acquisition of foreign language (FL) vocabulary involves two aspects: (1) learning to recognize a word's meaning, and (2) becoming able to retrieve or produce the word's form in speech production. The second aspect usually takes more time and practice to be developed. While learners may have no problem understanding a FL word's meaning, they frequently are unable to recall the word when necessary.

Probably the most frustrating form of word retrieval failures is the so-called tip-of-the-tongue (TOT) phenomenon: Sometimes we look for a certain word or phrase which we feel we know but at the time cannot find and articulate it. The word we are looking for (the target) seems to be on the tip of the tongue. Often we feel close to recalling the target, we know certain target features (a letter/sound, stress location), and we may associate words which are related in sound or meaning to the target (Brown \& McNeill, 1966). However, the complete target recall fails, and often minutes or hours pass until the sought-for item can be recovered.

\begin{tabular}{|l|l|l|l|l|}
\hline Ilha do Desterro & Florianópolis & $n^{\circ} 44$ & p.101-127 & jan./jun. 2003 \\
\hline
\end{tabular}


Much has been written about TOT states in L1 because the patterns of subjects' word search have often been seen as a "window" to the word retrieval processing mechanism (see Brown, 1991, for a review). However, TOT states also frequently arise with FL words, and this fact has potential for both the study of FL vocabulary acquisition and for theories of lexical representation and retrieval. This article will focus on FL TOT states, their structural properties, and what they suggest with respect to processes of lexical production.

\section{Causes of TOT States}

A few remarks have to be made regarding TOT state causation. Why TOT word retrieval fails is still under dispute. Two major hypotheses have been suggested with respect to the causes of (L1) TOT states: (a) the blocking hypothesis, and (b) the incomplete activation hypothesis. Proponents of blocking argue that target word recall fails because of another similar word which is competing and interfering with the target word's retrieval. The more frequently or more recently used associate is being activated or selected prior to the actually intended word. Once the associate is accessed, it blocks the recall of the target (e.g., Jones \& Langford, 1987; Priller \& Mittenecker, 1988; Reason \& Lucas, 1984).

The incomplete activation hypothesis proposes that word recall fails because the mapping between a word's meaning and its form cannot be realized or is completed only in part. The low frequency/ recency of use of target words is usually given as the major reason for retrieval failure (e.g., Burke et al., 1991). Associated words are not the cause, but merely a consequence or side effect of the recall failure; they may reflect how far word retrieval went before it got halted, and what attributes of the target words' form subjects have partially accessed (e.g., Brown \& McNeill, 1966; Burke et al., 1991; Meyer \& Bock, 1992).

Evidence has been provided for both the incomplete activation and the blocking hypotheses (see Brown, 1991). Ecke (1996) argued that most of the TOT states are due to incomplete activation and most 
associates are a consequence of target retrieval failure. Non-target words associated during a TOT state, however, can hinder (or "block") target recall if the speaker does not manage to withdraw attention from the (often closely related) associate. Blocking can be a cause for a TOT state when a subject becomes aware of a substitution error (a phonologically or semantically similar word that has automatically been selected instead of the target). In these (less frequent) cases, the speaker remains unable to redirect search successfully to the target (possibly because his focal attention remains on the non-target intrusion, the substitution error).

Most TOT states are assumed to occur with low frequency words and words that have not been used recently (Brown \& McNeill, 1966; Reason \& Lucas, 1984) although some studies indicate that under certain conditions (e.g., abrupt change of topic or language), medium and high frequency words (especially those with many semantically related words) can be subject to TOT states (Bak, 1987; Ecke, 1996; Heller, 1992). In FL word production, retrieval failures also occur with recently learned and used words. The overall frequency of use of these words is still low because of little productive usage. Failures of FL word recall are also frequently observed in cases of FL attrition after a longer period of non- or infrequent FL use (see Weltens \& Grendel, 1993). In both cases, the mapping procedure from (non-verbal) concept to linguistic form is weak and often not very reliable. Incomplete activation resulting in TOT states can be the consequence.

\section{The Two-Stage Model of Lexical Production}

Incomplete activation accounts are compatible with two-stage models of speech production (e.g., de Bot \& Schreuder, 1993; de Bot, 1992; Garrett, 1976, 1984; Levelt, 1989), which assume that word retrieval proceeds in two steps. At a first stage, a concept is specified semantically and syntactically. In other words, its meaning and grammatical category are determined. This step is also called grammatical encoding, and its product is the so-called "lemma" (Levelt, 1989). Important to note is 
that the word's sound structure is not yet available at this stage. Word form needs to be retrieved in a second step, which is called phonological encoding (see Figure 1).

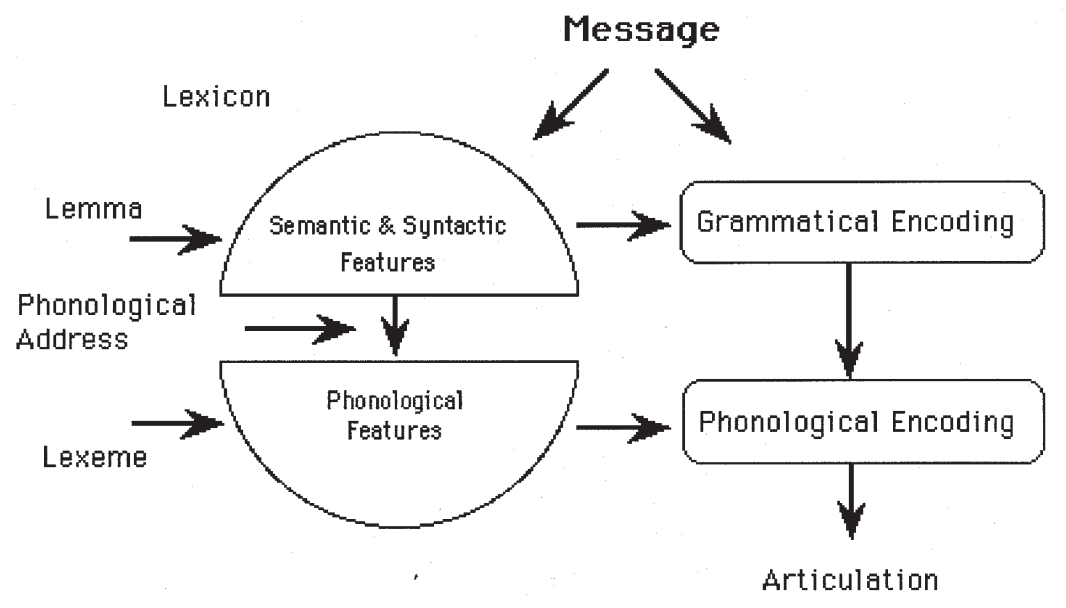

Figure 1. Different levels of representation within the language production system.

Note. From "Grammatical gender is on the tip of Italian tongues" by G. Vigliocco, T. Antonini, and M. F. Garrett, in press. Psychological Science.

TOT states have been cited as evidence for these models because they usually represent a retrieved lemma and only partially available form features. In other words, the mapping between lemma and form has failed. The frequent availability of certain key features of TOT targets, and similar features between targets and substitutes in substitution errors prompted Garrett (1984) to suggest that form features are retrieved via a "phonological address" (or "linking address") that comprises information about the target's number of syllables, major stress position, and first letter. The address features are accessed first and are then linked to the remaining form features. Fay \& Cutler (1977) presented a similar view suggesting that syllable length and 
main stress pattern are the organizing principles of the phonological lexicon.

Shattuck-Hufnagel $(1979,1992)$ and subsequently others argued for sub-stages of phonological encoding. In particular, the finding that spoonerisms ("a terry chart" instead of "cherry tart") most frequently involve the initial segment of the two interacting words pointed at a special status of the word onset. Further, the tendency was noted that segments generally interact with segments within the same syllabic position, i.e., initial segments interact with initial segments, final segments with final segments etc. This pattern suggests that interaction errors are also syllable-based. Based on the two position constraints sketched out above, "frame and filler models" were advanced. These models propose that phonological encoding initially involves the construction of a syllabic frame (a larger phonological unit in which major stress position and initial segment are assigned) and only subsequently other segments are "filled into" the frame. It is, however, not yet resolved what exactly constitutes the frame: Syllables of whole words or morphemes?

\section{Research Questions}

The major focus of this paper is whether the patterns of FL learners' naturally occurring TOT states are corroborative of two stage models of lexical production. In particular, it explores what subjects know about the FL target word that is on the tip of the tongue: Are first letter and syllable length key features of a possible linking address or an initial stage of phonological encoding? What kinds of non-target words are associated during the TOT search? In what way are they related to the target? Are they mainly similar in sound, in meaning, or in sound and meaning to the target? What are the most frequent underlying semantic relations between targets and associates? Which specific phonological features are shared by target-associate pairs? Are these patterns informative with respect to the time course of phonological encoding? 
Do TOT states with FL targets differ from TOT states reported with L1 targets?

\section{Method}

\section{Material, Design, and Procedure}

Structured cognitive diaries were used in this investigation to collect subject reports of naturally-occurring TOT states (see Cohen, 1996; Reason \& Lucas, 1984 on methodological issues). The participants were asked to record the TOT states that they experienced with L1 and FL words over periods of four-weeks. It was stressed that subjects should record what they knew and associated about the target immediately as the TOT state occurred and developed, and not in retrospect, in order to minimize subjective restructuring and forgetting processes. The TOT diary package consisted of one page of project explanation and instructions and eight structured answer sheets. The answer sheets asked for: the language of the target, a rating of "how well the target is known" from 1 (don't know it) to 5 (sure I know it), the number of syllables, known letters/sounds of the target, the sentence which the target was intended to be used in, non-target associates that came to mind during target word search, and the target. Subjects were also asked to keep record of the approximate time of associate and target recall. After the target was found, participants were asked to indicate how they found the target (the TOT resolution type). A copy of the diary answer sheets is provided in the appendix.

\section{Subjects}

One hundred nine subjects participated in this study, which was part of a larger investigation into TOT states in first and foreign languages (Ecke, 1996). Three groups of subjects were selected based on their native and foreign languages: native speakers of Russian studying English (R/E), native speakers of Spanish learning English 
(S/E), and U. S. American speakers of English studying German (E/G) at the time of the investigation. All subjects were young adult college students enrolled in a language course at the university level. The R/ E students were all majoring in a program of English at Voronezh State University, Russia. The S/E subjects were enrolled in courses of English at the University of Sonora in Hermosillo, Mexico, and the E/G subjects were enrolled in various courses of German at the University of Arizona. Subjects were administered a self-rating questionnaire in which they provided information on the age of beginning FL acquisition, an estimate of the frequency of FL use during the last six months on a fivepoint scale, and a rating of language proficiency on a five-point scale. The subject characteristics are illustrated in Table 1 below.

Table 1. Background characteristics of subjects

\begin{tabular}{lccc}
\hline & \multicolumn{3}{l}{ Groups of Subjects } \\
\cline { 2 - 4 } Characteristics & $\begin{array}{l}\text { English/ } \\
\text { German }\end{array}$ & $\begin{array}{l}\text { Russian/ } \\
\text { English }\end{array}$ & $\begin{array}{l}\text { Spanish/ } \\
\text { English }\end{array}$ \\
\hline n Subjects & 53 & 28 & 28 \\
M Age & 20.50 & 21.90 & 19.90 \\
FL Proficiency & 2.36 & 3.68 & 2.25 \\
FL Frequency of Use & 3.96 & 4.39 & 3.61 \\
M Beginning Age of FLA & 15.45 & 9.96 & 14.29 \\
\hline
\end{tabular}

Note: FL proficiency was rated on a five-point scale from 1 (very basic) to 5 (perfect). FL frequency of use was rated from 1 (never) to 5 (very frequently). FLA = foreign language acquisition.

The self-ratings provide a good general picture of the subjects' language acquisition history and their language proficiency. In various studies, bilinguals' and foreign language learners' self-assessment of language skills has been shown to be a reliable measure of language 
proficiency (e.g., Fishman \& Cooper, 1969; LeBlanc \& Painchaud, 1985; Bachman \& Palmer, 1989).

Students' language skills ranged from the beginning to the high intermediate levels on the ACTFL scale. Since this study's objective, however, was not to differentiate between TOT states in subjects at various levels of FL proficiency, the variability was not considered to be a problem. The subjects were paid for their participation, and some received extra credit in addition to the payment.

\section{Results}

Across all groups, 107 TOT states were recorded with FL targets. These represent about $20 \%$ of the overall TOT data corpus in Ecke (1996), i.e., the large majority of TOT state records (which will not be reported here) were of the various first languages. See Ecke (in press) for a comparison of TOT states with FL targets and TOT states with L1 targets. Forty-five (mostly German) FL TOT states were recorded by the American subjects, 30 TOT states with English FL targets were searched for by the Russian subjects, and 32 English FL words were TOT targets recorded by the Mexicans. The greatest number of the target words across all groups were nouns ( $49.5 \%$ ), verbs made up $24.3 \%$ of the targets, adjectives constituted $14 \%$, proper names $9.3 \%$, and $2.8 \%$ were other word types. The distribution of FL target word types in this study is different from the distribution of L1 target word types reported in other studies. Proper names (an infrequent category of FL TOT states) have been reported as the most frequent target word type in L1 TOT states (e.g., Burke et al., 1991; Cohen \& Faulkner, 1986).

\section{Fragmentary Information}

The subjects' reports about the targets' letters (initial, middle, and final) and the number of syllables were analyzed. The percentages of correct recordings of these attributes are illustrated in Table 2. 
Table 2: Numbers of syllables and letters reported for FL targets within and across groups

\begin{tabular}{lccccc}
\hline \multirow{5}{*}{ Group } & \multicolumn{6}{l}{ Fragmentary Information } & & \\
\cline { 2 - 6 } & $\underline{\mathrm{n}}$ & $\begin{array}{c}\text { \#Syllables } \\
\%\end{array}$ & $\begin{array}{c}\text { I. Letter } \\
\%\end{array}$ & $\begin{array}{c}\text { M. Letters } \\
\%\end{array}$ & $\begin{array}{c}\text { F. Letter } \\
\%\end{array}$ \\
\hline English/German & 43 & 55.8 & 44.2 & 20.9 & 25.6 \\
Russian/English & 28 & 53.6 & 46.2 & 46.4 & 25.0 \\
Spanish/English & 32 & 56.3 & 28.1 & 9.4 & 15.6 \\
All & 103 & 55.3 & 39.8 & 24.3 & 22.3 \\
\hline
\end{tabular}

Note: \# Syllables = number of syllables; I. Letter = initial letter; M. Letter = middle letters; F. Letter $=$ final letter.

Subjects in all groups did quite well in guessing the right number of the targets' syllables. The first letter was also provided frequently, across groups significantly more often than middle and final letters. This may suggest that initial letters/sounds and syllable length are retrieved early within the phonological encoding process of FL words, and that they could be key features constituting a linking address or a phonological frame which is accessed prior to other (less salient) segments.

\section{Target - Associate Relation}

Subjects in a TOT state frequently associated other words while searching for the target. $74.8 \%$ of the FL TOT states across all groups involved one or more word associates. $79.5 \%$ of all the associates shared the syntactic class with the respective targets. Most of the associates were of the same language as the target (intralingual associates), only $24 \%$ were of a different language, almost exclusively the first language (interlingual associates). All target - associate pairs (including intraand interlingual associates) were analyzed with respect to their similarity in sound and/or meaning. Example (1) is a record of a TOT 
state that involves associates similar in meaning; example (2) illustrates a TOT state that includes associates similar in sound to the target.

(1)American subject searching for Augen [eyes] Search Time FOK: 4, Syllables: 1, Letters: O, e

$\mathrm{Au}$

Ohren[ears]

Kopf [head

Knee

Fuss [foot]

Augen [eyes]
$1 \mathrm{sec}$

$3 \mathrm{sec}$

$4 \mathrm{sec}$

$6 \mathrm{sec}$

$7 \mathrm{sec}$

$4 \mathrm{~min}$

"I sang the head and shoulder song till it came to me. Singing little songs helped me to think and get the words straight in my mind."

(2)Russian subject searching for concussion FOK: 4, syllables: 3 , sound [k] conclusion concurrence concussion
Search Time

$15 \mathrm{~min}$

$1: 20 \mathrm{~h}$

$1: 49 \mathrm{~h}$

"Having given up the idea of searching my memory I've looked the lost word up in the Russian English dictionary, because I was sure of the word's Russian equivalent 'sotriasenie'."

Table 3 displays more examples of target - associate pairs similar in sound (SS), pairs similar in meaning (SM), and pairs similar in sound and meaning (SSM). Table 4 below displays the percentages of the three relation types. 
Table 3: Examples of target-associate relation types

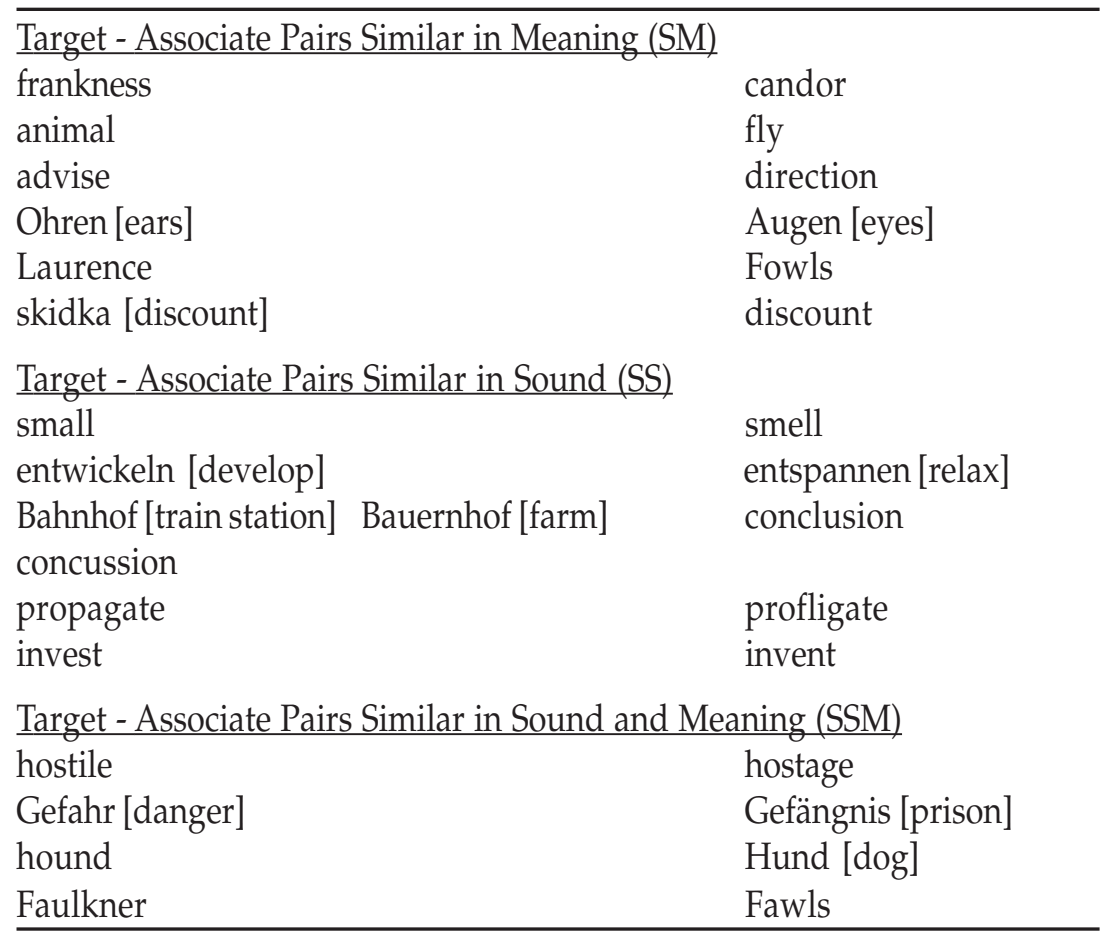

Note: The left column represents the associates, the right column lists the targets.

Table 4: Target - associate relation types in FL TOTs within and across groups

\begin{tabular}{|c|c|c|c|c|}
\hline \multirow[b]{2}{*}{ Group } & \multicolumn{4}{|c|}{ Relation Type } \\
\hline & $\begin{array}{c}\text { SS } \\
\%\end{array}$ & $\begin{array}{r}\mathrm{SM} \\
\%\end{array}$ & $\begin{array}{l}\text { SSM } \\
\%\end{array}$ & $\mathrm{n}$ \\
\hline $\mathrm{E} / \mathrm{G}$ & 52.9 & 31.4 & 15.7 & 51 \\
\hline $\mathrm{R} / \mathrm{E}$ & 42.3 & 19.2 & 38.5 & 26 \\
\hline$S / E$ & 26.3 & 55.3 & 55.3 & 38 \\
\hline All & 41.7 & 36.5 & 21.7 & 115 \\
\hline
\end{tabular}

Note: The absolute number of target - associate pairs $(\underline{n})$ is higher than the number of TOT states because some TOT states involved more than one associate. SS = similar in sound; $\mathrm{SSM}=$ similar in sound and meaning; $\mathrm{SM}=$ similar in meaning. 
It is not very surprising that subjects associated words that are similar in meaning to the sought-for target. SM associates represent $36.5 \%$ of all associates. The target-associate pairs classified as SM and SSM $(\underline{n}=67)$ were further categorized into semantic relation types: Most of the associates were synonyms (34.3\%), category members $(26.9 \%)$, or attributes $(17.9 \%)$ with respect to the target. Superordinate, subordinate, antonym, and associative relations were relatively rare compared to the three major types above.

Perhaps the most important finding of this study is the high percentage of associates similar in sound to the target (41.7\%). The remaining target-associate pairs $(21.7 \%)$ were related in both sound and meaning. The SS target-associate pairs $(\underline{n}=48)$ were further examined with respect to shared phonological attributes. Targetassociate similarity was analyzed for the following phonological features: number of syllables, initial letter/sound, root onset, middle letters/sounds, final letter/sound, and main stress position. The results are illustrated in table 5 .

Table 5: Percentage of phonological attributes similar in target associate pairs

\begin{tabular}{lc}
\hline Phonological Attribute & Target - Associate Similarity in \% \\
\hline Number of Syllables & 52.2 \\
Main Stress Position & 73.9 \\
Initial Letter & 72.5 \\
Root Onset Letter & 78.3 \\
Middle Letters & 63.8 \\
Final Letter & 53.6 \\
\hline
\end{tabular}

Note: The chance level for similarity of middle letters is higher than for the other attributes because more than one segment can be similar. The other conditions reflect the comparison of only one attribute. 
In general, high degrees of overall similarity in form could be found. However, the highest degree of target-associate similarity was found in the following three categories: The associates' root onset $(78.3 \%$ of the times), main stress position (73.9\% of the times), and initial letter $(72.5 \%)$ coincided most frequently with the corresponding target features. Middle letters (63.8\%), final letter (53.6\%) and number of syllables $(52.2 \%)$ showed less frequent overlap in form.

\section{Discussion}

This study investigated tip-of-the-tongue states with momentarily inaccessible foreign language words. It was asked whether the structural patterns of foreign language TOT states were corroborative of two stage models of lexical production. The fragmentary information available to subjects about the target word and the similarity between target words and non-target associates were analyzed to illuminate this question.

\section{Fragmentary Information}

The analysis of fragmentary information reported by the subjects about the target revealed that number of syllables and first letter are more often accessed than middle and final letters in FL TOT states. (Main stress position was not requested in the diary questionnaire.) The fact that the number of syllables of the target was frequently predicted correctly can be interpreted as support for the view that syllabic structure is part of a phonological frame or address via which the output of grammatical encoding is mapped onto phonological form. However, one has to take into account that the variation in number of syllables of the target words is rather low and that therefore correct guessing probabilities are rather high.

The high recall rate of initial letters is generally consistent with data from L1 TOT states and supports what has been assumed about the special status of the initial segment in word recall (Garrett, 1984; 
Shattuck-Hufnagel, 1979, 1992). However, it must be noted that the percentage of middle and final letter recall of FL targets is higher than for L1 TOT states (see Ecke, 1997). Subjects appear to be more sensitive to a greater variety of phonological attributes of temporarily inaccessible FL words compared to L1 TOT targets. In other words, the difference between the high rate of initial letter recall and the recall rate of middle and final letters is greater for L1 TOT states than for FL TOT states. This greater sensitivity to FL word form appears to have an interesting parallel in children's L1 production. Data on children's substitution errors (Aitchison \& Straf, 1981) show that target and intrusion show a greater variety of sound similarity compared to adult's speech errors (which mostly coincide in syllable length and initial letters). Ecke (in press) suggested that the process of acquiring and strengthening any type of vocabulary representation may require that the learner attend to a wide range of attributes, not only to key attributes such as the initial letter. With an increased strength of sound representations and automatized retrieval procedures, a few key attributes will gain importance, and less salient features will become redundant in the triggering of complete word form recall.

\section{Target-Associate Relation}

Most of the non-target word associates were either similar in sound $(41.7 \%)$ or similar in meaning $(36.5 \%)$ to the target word. The remaining $21.7 \%$ of the target-associate pairs were similar in sound and meaning. The latter probably reflect (at least in part) higher-order strategic search processes in which subjects use the output patterns of various representational levels as cues for continuous word search (see Ecke, 1997). The two major groups, however, speak for the existence of two segregated representational levels, one for meaning and another one for form (phonology) of FL words, and are consistent with two-stage models of lexical production (Garrett, 1976, 1984; Levelt, 1989). Both representational levels are organized differently and access procedures are governed by different criteria. 
A related phenomenon observable in FL learners' speech production, but often overlooked because of researchers' focus on L1 transfer, underscores the dissociation of meaning and sound-level representations. Both in oral and written performance, FL speakers occasionally make substitution errors which are strikingly similar in sound to the target, but completely different in their meanings. Another group of errors displays a close meaning relationship to the target without similarity in sound. Below, we present a few examples of sound-related and meaning-related errors, which are from an on-going study of errors in learners of German as a FL (Ecke \& Hall, 1997). The intrusions are underlined and the actual targets are given in parentheses.

(3) "Wenn ich liebe ich denke nicht an Geschlecht (Chinesisch oder nicht)." (Rasse)[When I am in love, I do not think about gender (Chinese or not).] (race)

(4) "Es ist hilfreich, wenn ein Lehrer die Studenten erzählt, ob sie die Informationen gut oder schlecht in der Klasse verstehen." (fragt)[It is helpful, if a teacher tells the students whether they understood the information well or badly in class.] (asks)

(5) "Die Süddeutschen essen Nudeln und Füße." (Klöße) [The Southern Germans eat pasta and feet.] (dumplings)

(6) "Das war das erste mal, daß Steffi Martina Navratilova geschlafen, hm, geschlagen hat." [That was the first time that Steffi slept, hm, bet Martina Navratilova.]

In examples (3) and (4), the error is the result of a misselection at the lemma level. The target words were substituted by entries that are related in meaning and that share syntactic class. There is, however, no similarity in the words' sound patterns. Examples (5) and (6), on the 
other hand, illustrate an error type which is based upon the inaccurate selection of lexical form, i.e., phonology. Target and substitute are very close in their sound patterns, but do not reveal any similarity in meaning. The similar patterns between (a) FL substitution errors and targets and (b) FL TOT targets and associates point to the same two modules of lexical processing: lemma selection (semantic/syntactic specification) and phonological encoding.

The analysis of TOT associates similar in meaning with respect to specific semantic relation types was carried out because it may point at possible principles which underlie the organization and representation of lexical meaning. In this analysis, synonymy (war - Krieg [war]), category membership (job - hobby) and, to a certain extent, attributive relations (hostile - hostage) were identified as the most frequent relation types. Synonyms, attributes, and category members are probably the items that would serve best as elements in what Kellermann (1991) called "conceptual" communication strategies, at least, for retrieval problems of nouns, the most frequent word type of FL targets in this study. Thus, the organization of the lexical store of meaning could be characterized as "communication-friendly" or "ready to compensate" for lexical retrieval problems. For a discussion of FL communication strategies and possible taxonomies, see Dörnyei \& Scott (1997), Faerch \& Kasper (1983), Poulisse (1993), and Ridley \& Singleton (1995).

However, the fact that the greatest number of the associated words $(41.7 \%)$ were related solely in terms of sound (without any identifiable meaning relation to the target) is not explainable in terms of strategy use for communication. Instead, we would like to suggest that the similar sound features and the different meaning features of this group of associates reflect partially retrieved form features from a representational (phonological) level which is dissociated from the store of word meaning (see also Meyer \& Bock, 1992). The phonological store is organized solely according to phonological principles. TOT states are, generally speaking, instances of partial word retrieval in which the target's lexical meaning and syntactic class have been specified, and in which partial phonological information is available. 
The access of fragments of the target's phonology may trigger the recall of a complete non-target word which can be totally unrelated in meaning but shares the key form features of the target.

It is an open question whether this triggering of a non-target word form is the result of activation spreading (e.g., Dell \& O'Seaghdha, 1992) within the phonological store or whether the fragmentary information (as incomplete output) serves as a new input pattern for the (constantly) monitoring comprehension system. This fragmentary input may prompt the successive search for a matching entry in the phonological store.

A question of import is whether the phonological information available to the speaker as fragmentary target attributes or in targetrelated associates shows consistent patterns which allow us to infer something about the principles of phonological encoding. The analysis of phonological similarity between target and associates revealed that root onset, major stress position, and initial letter are the attributes that most frequently coincide in FL TOT states. These features appear to be retrieved early within phonological encoding; they may be part of what Garrett (1984) suggested to be a linking address, or what ShattuckHufnagel $(1992,1979)$ described as a phonological frame. Interestingly, number of syllables was not among the three criteria that shared the highest rate of similarity. This may suggest that syllable length of words per se is not necessarily a part of the linking address or phonological frame, at least for FL words. It seems more likely that morphological composition processes are involved in lexical production and that number of syllables is only a key feature within certain word components (perhaps within the word stem). The high rate of overlap in root onset appears to be consistent with this assumption. Root morphemes may be retrieved separately from other (to-be-specified) morphemes which are added on to the root in morphological composition processes.

The distribution of target-associate relations in FL TOT states differs from the distribution of relation types reported for L1 TOT states: Of the L1 target-associate pairs in Ecke (1996, in press), 17\% were SS, 
30\% were SSM, and 53\% were SM. Kohn et al. (1987) reported similar patterns: $20 \%$ of the associates were SS, $25 \%$ SSM, and $54 \%$ SM to the target. In these studies, subjects' search for L1 targets was more frequently accompanied by meaning-related associations. Associates similar in sound are less frequent in L1 TOT states than in FL TOT states (however, see Brown \& McNeill, 1966, who also reported high rates of SS associates in L1 TOT states.) The high percentage of pure SS associates for FL targets resembles data from children's responses to word association tests in their L1 (Söderman, 1989, 1993; cited in Singleton, in press). These studies report that children produce a higher rate of SS associates to word primes compared to adults, who associate more SM words to the same word primes. The high rates of SS associates in FL learners' word search and children's L1 word associations may, like the greater variety of attended sound cues in adult FL learners and child L1 learners suggested above, point to a particular form sensitivity of speakers at early stages of vocabulary acquisition. Since this sound sensitivity for relatively recently learned words does not appear to be restricted to FL words, we do not interpret this feature as unique or qualitatively different for the FL (L2) lexicon (see Singleton, in press, for similar arguments). It is more likely that form-focused processing is a general temporal disposition which is necessary for the learner to integrate new words (no matter whether of L1, L2 or L3) into the phonological store of the lexicon (see also Ecke \& Hall, 1997; Hall, 1992).

\section{Conclusion and Implications}

Empirical data for lexical retrieval failures are difficult to collect. The database reported here for naturally-occurring TOT states with FL words is rather small. In spite of this, we believe that the analysis of fragmentary target information and target-associate relation types in FL TOT states has provided evidence for the existence of two separate processing stages in lexical production: (1) grammatical (semantic/ syntactic) encoding and (2) phonological encoding, and their disjunct 
organization (Garrett, 1984, 1993; Levelt, 1989). Further, we suggested a robust pattern in extended lexical search for FL words: subjects' particular focus on word form (phonology). We pointed out the importance of possible key attributes for phonological encoding: root onset, major stress position, initial letter. The investigation of these patterns in ongoing and future studies may further illuminate the working mechanism of the phonological lexicon.

The processing mechanisms suggested above may be relevant with respect to the teaching and practice of productive FL skills: Contextual activities and the use of advance organizers (e.g., brainstorming) before tasks of lexical production appear useful in at least two aspects: The activation or priming of episodic/semantic knowledge structures is likely to better prepare the speaker for specific target recall and for the use of communication strategies (e.g., paraphrasing, synonym use etc.) when retrieval of a specific target fails (see Dörnyei \& Scott, 1997; Faerch \& Kasper, 1983; Poulisse, 1993; Ridley \& Singleton, 1995). Some word finding problems which have been suggested to be caused by abrupt changes in topic, situation, or language (Ecke, 1996; Wenzl, 1932) can be avoided if preparatory ("warm-up") activities with respect to topic, situation, or context are applied.

The structure and functioning of the phonological store imply the following for FL vocabulary development: New words are memorized and stored based upon their phonological similarity to already known words (probably in key features under a linking address or a phonological frame). Sound similarity to a known word in L1, L2 or L3 can be used to integrate the new word form into the phonological store. Lexical representation and processing based upon similar appearance, however, can also cause confusion or faulty word selection in productive tasks (Ecke \& Hall, 1997). Details (less salient attributes which are not part of the linking address or frame) that differentiate close words have to be analyzed and noticed by the learner. The reported range of available partial phonological attributes of inaccessible FL words and 
the high rate of phonologically similar associates suggest that this analysis is actually conducted by the learner. Much of this form sensitivity and analysis may be unconscious or restricted to instantaneous "noticing" (see Schmidt, 1991), but it certainly seems necessary to discriminate between new words and already known words, and to integrate the new items into the phonological lexicon. Sensitivity to word forms (sound and spelling), and to the similarities and differences between lexical items is part of the acquisition process and necessary for the reduction of errors in lexical production. Intervention to foster this form sensitivity (e.g., pronunciation and spelling exercises and the usage of references, especially dictionaries) may help to clarify or disambiguate a new word's form. Especially novice learners may have to be familiarized with the different types of dictionaries that they can use as tools for FL vocabulary learning.

\section{Note}

1 This study was supported in part by a McDonnel-Pew Cognitive Neuroscience grant to the University of Arizona and by a Summer Research Support Grant by the University of Arizona Graduate College. An earlier Spanish version of this paper was presented under the title "Las fases de recuperación de palabras momentáneamente inaccesibles en un idioma extranjero" at "El IV Encuentro Internacional de Lingüística en el Noroeste", Hermosillo, México, in November 1996.

\section{References}

Aitchison, J., \& Straf, M. (1981). Lexical storage and retrieval: A developing skill? Linguistics, 19, 751-795.

Bak, B. (1987). The tip-of-the-tongue phenomenon: A Polish view. Polish Psychological Bulletin, 18, 21-27.

Bachman, L. F., \& Palmer, A. S. (1989). The construct validation of self-ratings of communicative language ability. Language Testing 6, 14-29. 
Brown, A. S. (1991). A review of the tip-of-the-tongue experience. Psychological Bulletin, $109,202-223$.

Brown, R., \& McNeill, D. (1966). The "tip of the tongue" phenomenon. Journal of Verbal Learning and Verbal Behavior, 5, 325-337.

Burke, D. M., MacKay, D. G., Worthley, J. S., \& Wade, E. (1991). On the tip of the tongue: What causes word finding failures in young and older adults? Journal of Memory and Language, 30, 542-579.

Cohen, A. D. (1996). Verbal reports as a source of insights into second language learner strategies. Applied Language Learning, 7, 5-24.

Cohen, G., \& Faulkner, D. (1986). Memory for proper names: Age differences in retrieval. British Journal of Developmental Psychology, 4, 187-197.

Dörnyei, Z., \& Scott, M. L. (1997). Communication strategies in a second language: Definitions and taxonomies. Language Learning, 47, 173-210.

de Bot, K. (1992). A bilingual production model: Levelt's "speaking" model adapted. Applied Linguistics, 13, 1-24.

de Bot, K., \& Schreuder, R. (1993). Word production and the bilingual lexicon. In R. Schreuder \& B. Weltens (Eds.), The bilingual lexicon (pp. 191-214). Amsterdam: John Benjamin.

Dell, G. S., \& O'Seaghdha, P. G. (1992). Stages of lexical access in language production. Cognition, 42, 287-314.

Ecke, P. (in press). Tip of the tongue states in first and foreign languages: Similarities and differences of lexical retrieval failures. Proceedings of the EUROSLA 7 Conference. Barcelona, Spain.

Ecke, P. (1997). Foreign language learners' retrieval strategies for words that are on the tip of the tongue. Manuscript submitted for publication.

Ecke, P. (1996). Cross-language studies of lexical retrieval: Tip-of-the-tongue states in first and foreign languages. Unpublished doctoral dissertation, University of Arizona, Tucson, USA. 
Ecke, P., \& Hall, C. J. (1997, October). Tres niveles de la representación mental: Evidencia de errores léxicos en estudiantes de lenguas extranjeras. Paper presented at IV Congreso Nacional de Lingüística, Xalapa, Veracruz, México.

Faerch, C., \& Kasper, G. (1983). Plans and strategies in foreign language communication. In C. Faerch \& G. Kasper (Eds.), Strategies in interlanguage communication (pp. 20-60). London: Longman.

Fay, D., \& Cutler, A. (1977). Malapropisms and the mental lexicon. Linguistic Inquiry, $8,505-520$.

Fishman, J. A., \& Cooper, R. L. (1969). Alternative measures of bilingualism. Journal of Verbal Learning and Verbal Behavior, 8, 276-282.

Garrett, M. F. (1993). Errors and their relevance for models of production. In G. Blanken, J. Dittmann, H. Grimm, J. C. Marshall \& C.-W. Wallesch, (Eds.), Linguistic disorders and pathologies (pp. 72-92). Berlin, New York: Walter de Gruyter.

Garrett, M. F. (1984). The organization of processing structure for language production: Application to aphasic speech. In D. Caplan, A. Lecours \& A. Smith (Eds.), Biological perspectives on language (pp. 172-193). Cambridge, MA: MIT Press.

Garrett, M. F. (1976). Syntactic processes in sentence production. In R. J. Wales \& E. Walker (Eds.), New approaches to language mechanisms (pp. 231-256). Amsterdam: North Holland.

Hall, C. J. (1993). Making the right connections: Vocabulary learning and the mental lexicon. Puebla, México: Universidad de las Américas. (ERIC Document Reproduction Service No. ED 363 128)

Heller, R. B. (1992). On the relation between tip-of-the-tongue states and word finding problems of older adults. Unpublished doctoral dissertation, University of Alberta, Canada.

Jones, G. V., \& Langford, S. (1987). Phonological blocking in the tip of the tongue state. Cognition, 26, 115-122.

Kellerman (1991). Compensatory strategies in second language research: A critique, a revision, and some (non-) implications for the classroom. In R. Phillipson, E. Kellerman, L. Selinker, M. Sharwood Smith \& M. Swain (Eds.), Foreign second 
language pedagogy research: A commemorative volume for Claus Faerch (pp. 142-161). Clevedon: Multilingual Matters Ltd.

LeBlanc, R., \& Painchaud, G. (1985). Self-assessment as a second language placement instrument. TESOL Quarterly 19, 673-687.

Levelt, W. J. M. (1989). Speaking: From intention to articulation, Cambridge, MA: MIT Press.

Meyer, A. S., \& Bock, K. (1992). The tip-of-the-tongue phenomenon: Blocking or partial activation? Memory and Cognition, 20, 715-726.

Poulisse, N. (1993). A theoretical account of lexical communication strategies. In R. Schreuder \& B. Weltens (Eds.), The bilingual lexicon (pp. 157-189). Amsterdam: John Benjamins Publishing Company.

Priller, J., \& Mittenecker, E. (1988). Experimente zum Unterschied von "Wort auf der Zunge" und "Gefühl des Wissens". Zeitschrift für Experimentelle und Angewandte Psychologie, 35, 129-146.

Reason, J. T., \& Lucas, D. (1984). Using cognitive diaries to investigate naturally occurring memory blocks. In J. E. Harris \& P. E. Morris (Eds.), Everyday memory, actions and absentmindedness (pp. 53-70). London: Academic Press.

Ridley, J., \& Singleton, D. (1995). Contrastivity and individual learner contrasts. Fremdsprachen Lehren und Lernen, 24, 123-137.

Schmidt, R. (1990). The role of consciousness in second language learning. Applied Linguistics, 11, 129-158.

Shattuck-Hufnagel, S. (1992). The role of word structure in segmental serial ordering. Cognition, 42, 213-259.

Shattuck-Hufnagel, S. (1979). Speech errors as evidence for a serial order mechanism in sentence production. In W. E. Cooper \& E. T. C. Walker (Eds.), Sentence processing (pp. 295-342). Hillsdale, NJ: Erlbaum.

Singleton, D. (in press). Learning and processing L2 vocabulary. Language Teaching. 
Vigliocco, G., Antonini, T., \& Garrett, M. F. (in press). Grammatical gender is on the tip of Italian tongues. Psychological Science.

Weltens , B., \& Grendel, M. (1993). Attrition of vocabulary knowledge. In R. Schreuder \& B. Weltens (Eds.), The bilingual lexicon (pp. 135-156). Amsterdam: John Benjamins Publishing Company.

Wenzl, A. (1932). Empirische und theoretische Beiträge zur Erinnerungsarbeit bei erschwerter Wortfindung. Archiv für die gesamte Psychologie, 85, 181-218. 


\section{APPENDIX: DIARY ANSWER SHEET}

Name: Date and Time TOT occurred: Date and Time TOT resolved:

1. Language of target:

2. Please rate how well you know the word? $\begin{array}{lllllll}\text { Not very well } & 1 & 2 & 3 & 4 & 5 & \text { Sure I know it. }\end{array}$

3. Guess any features that you know about the word. Mark your confidence:

Letters/sounds? $1 \quad 2 \quad 3$ $\begin{array}{lllllllll}\text { Number of syllables? } & 1 & 2 & 3 & 4 & \text { more } & 1 & 2 & 3\end{array}$ Article?

Gender? $1 \quad 2 \quad 3$

Other: $1 \quad 2 \quad 3$

$1 \quad 2 \quad 3$

4. Define or describe the meaning of the word:

5. Write the sentence or context in which you wanted to use the word. Put a blank where the target would occur:

6. Which words/sounds (if any) come into mind while you are searching? Include the target if found eventually.

Words/sounds Time word appears after initial search (in sec/min/h)
Persistence of word

weak strong

$\begin{array}{lll}1 & 2 & 3\end{array}$

$\begin{array}{lll}1 & 2 & 3\end{array}$

$\begin{array}{lll}1 & 2 & 3\end{array}$

123

133


Target word (if found):

7. How did you get the target? Circle number.

1: Target "popped up" later when I did not think about it.

2: I searched my memory. I used the following strategy:

3: Some context in the environment/situation triggered the target.

4: I heard the target from someone else / I read the target somewhere else.

5: Ilooked up the target in a dictionary/book.

6: I consulted a person

7: Other:

8. Do you feel that the associated word(s) listed in (6) helped or blocked finding the target? Also judge how frequently and how recently you have used these words. List word(s) and circle numbers respectively.

\begin{tabular}{|c|c|c|c|c|c|c|c|c|c|}
\hline \multirow[t]{2}{*}{ Word } & \multirow[t]{2}{*}{$\begin{array}{l}\text { blocks } \\
\text { target }\end{array}$} & \multirow[t]{2}{*}{$\begin{array}{l}\text { don't know } \\
\text { target of }\end{array}$} & \multirow[t]{2}{*}{$\begin{array}{l}\text { helps } \\
\text { finding }\end{array}$} & \multicolumn{3}{|c|}{ frequency } & \multicolumn{3}{|c|}{$\begin{array}{l}\text { recency } \\
\text { of use }\end{array}$} \\
\hline & & & & low & & (811 & long & & recent \\
\hline & $\begin{array}{lll}-3 & -2 & -1\end{array}$ & $0+1+2+$ & & 1 & 2 & 3 & 1 & 2 & 3 \\
\hline & $\begin{array}{lll}-3 & -2 & -1\end{array}$ & $0+1+2+$ & & 1 & 2 & 3 & 1 & 2 & 3 \\
\hline & $\begin{array}{lll}-3 & -2 & -1\end{array}$ & $0+1+2+$ & & 1 & 2 & 3 & 1 & 2 & 3 \\
\hline & $\begin{array}{lll}-3 & -2 & -1\end{array}$ & $0+1+2+$ & & 1 & 2 & 3 & 1 & 2 & 3 \\
\hline & $\begin{array}{lll}-3 & -2 & -1\end{array}$ & $0+1+2+$ & & 1 & 2 & 3 & 1 & 2 & 3 \\
\hline
\end{tabular}

9. When did you use the target last time?

$$
\begin{array}{lll}
\text { long time ago } & \text { just recently } \\
1 & 2 & 3
\end{array}
$$

10. How often have you used the target?

$\begin{array}{lll}\text { very rarely } & \text { sometimes } & \text { frequently } \\ 1 & 2 & 3\end{array}$


11. Does the targetno somewhat yes confirm with all the 2 3 features you initially predicted (in 3)?

Explain if necessary.

12. Give any information you think relevant or interesting about the target and its relation to predicted features and associated words. 